\title{
Severo Sarduy, el neobarroco y las POLÍTICAS DE LA LITERATURA
}

SEVERO SARDUY, THE NEO-BAROQUE AND THE

POLITICS OF LITERATURE

Ignacio Iriarte

Universidad Nacional de Mar del Plata/CONICET

Mar de Plata, Argentina

\section{Resumen}

En este trabajo abordo las relaciones entre política y literatura que desarrolló Severo Sarduy a lo largo de su carrera. El punto de partida es el lugar problemático que ocupó como exiliado cubano y como un escritor que orientó su obra hacia una nueva forma de revolución. El trabajo tiene dos propósitos centrales. En primer lugar, describir una serie de textos (los ensayos que publicó en Mundo Nuevo, Cobra y La simulación) en los que Sarduy expone esta nueva concepción de la política y, en segundo lugar, reparar en la disolución del programa revolucionario y el desarrollo de una escritura autobiográfica y desengañada.

Palabras claves: Neobarroco, literatura, revolución.

\begin{abstract}
In this work I discuss the relations between politics and literature developed by Severo Sarduy throughout his career. The starting point is the problematic place he occupied as a Cuban exiled and as a writer who guided his work towards a new form of revolution. The work has two central purposes. First, the paper aims to describe some texts (the essays published in Mundo Nuevo, Cobra and La simulación) in which Sarduy exposes his new conception of politics; secondly, the work aims to analyze, in his work, the dissolution of the revolutionary program and the development of an autobiographical and disillusioned writing.
\end{abstract}

Keywords: Neo-Baroque, literature, revolution.

\section{Resumo}

Neste trabalho analiso as relaçóes entre política e literatura desenvolvidas por Severo Sarduy ao longo de sua carreira. O ponto de partida é o lugar problemático que ocupou como exilado cubano e como escritor que orientou sua obra para uma nova forma de revolução. $\mathrm{O}$ trabalho tem duas finalidades centrais. Em primeiro lugar, pretende-se descrever uma série de textos (os ensaios publicados em Mundo Nuevo, Cobra e La simulación) em que Sarduy expóe sua nova concepçáo de política; em segundo lugar, o trabalho visa analisar na dissoluçáo do programa revolucionário e o desenvolvimento de uma escrita autobiográfica e desiludida.

Palavras-chave: Neobarroco, literatura, revolução. 
Al final de "El Barroco y el Neobarroco", que publica en América Latina en su literatura (1972), Severo Sarduy afirma, con un convencido optimismo, que su recuperación del Barroco enarbola las banderas de una nueva revolución:

Barroco que en su acción de bascular, en su caída, en su lenguaje pinturero, a veces estridente, abigarrado y caótico, metaforiza la impugnación de la entidad logocéntrica que hasta entonces lo y nos estructuraba desde su lejanía y su autoridad; barroco que recusa toda instauración, que metaforiza al orden discutido, al dios juzgado, a la ley transgredida. Barroco de la Revolución (1999: 1404). ${ }^{1}$

Rafael Rojas (2013) sostiene que estas palabras deben leerse en el marco del tránsito que Sarduy hace de Cuba a Francia. Desde el principio de su carrera, el autor se ligó a la modernidad del campo intelectual cubano: Sarduy colaboró en Ciclón, Lunes de revolución y Revolución, reivindicó el sartrismo, se mantuvo cerca, en tres de sus cuatro relatos cubanos, del absurdo de Virgilio Piñera, defendió el arte abstracto, a pesar del giro hacia la pintura concreta que se produjo en 1959, y escribió su primera novela, ya en Francia, tomando las principales técnicas del nouveau roman ${ }^{2}$. Esta formación intensa, y su relación amorosa con François Wahl, explican su rápida inserción en la vanguardia parisina. Desde mediados de los años sesenta, Sarduy articuló su obra con las concepciones estético-políticas que estaban desarrollando los principales referentes de la intelectualidad parisina. Rojas lo demuestra por medio de "Sarduy: la face baroque" (1967), reseña que Rolland Barthes hizo sobre De donde son los cantantes (1967), en la que conecta el texto con la idea de que "la economía política de los símbolos, correspondiente a la nueva fase capitalista, demandaba una revolución del concepto de revolución" (ROJAS, 2013: 84). Esta concepción de la escritura ya estaba presente, además, en "Sur Góngora” (1966), que publicó en Tel Quel, ensayo que fue retomado por el propio Barthes (1996) en Critica y verdad, en donde afirma, apoyándose en Sarduy, que hay que superar "la pobre ironía volteriana" y desarrollar una ironía barroca (1996: 78). Instalado en esta red, Sarduy logró dos cosas en principio imposibles: transformó el Barroco en un lenguaje subversivo y

\footnotetext{
${ }^{1}$ Excepto expresa mención, cito los textos de Sarduy de la Obra completa (1999). Para mayor claridad, en cada mención que hago de los libros de Sarduy ańado el año de la edición original.

${ }^{2}$ Los textos cubanos han sido recogidos por Cira Romero en Severo Sarduy en Cuba. El Nouveau Roman había impactado en Cuba y todavía estaba en debate cuando salió Gestos. Así lo demuestra la polémica entre José Antonio Portuondo y Ambrosio Fornet de 1964, que recoge Graziela Pogolloti (2006: 249-325).
} 
afirmó, a pesar de ser un exiliado cubano, que en su escritura se dirimía una nueva revolución.

En los años setenta, esta posición era problemática, no en el sentido de que Sarduy estuviera equivocado, sino en tanto era algo que para la época todavía se revelaba marcado por la imposibilidad. Por una parte, su literatura se inscribe en las reivindicaciones libertarias de la izquierda europea post-' 68 $y$, consecuente con este clima, impugna un orden que está tejido alrededor de definiciones totalizantes, socavando énfasis las legitimidades a-históricas de las subjetividades y las sociedades. En este aspecto, la propuesta de Sarduy puede comprenderse como el pasado mańana del pensamiento estético y político, desde el desarrollo del neobarroco en América Latina a abordajes posteriores como La modernidad de lo barroco, de Bolívar Echeverría (1998). Pero para los años setenta la obra de Sarduy era difícil de pensarla dentro de la izquierda, porque la izquierda se inclinaba hacia el socialismo y tenía como referencia la revolución cubana. Es cierto que el caso Padilla quebró el consenso sobre la Revolución, algo que puso de relieve Claudia Gilman (2003), pero se mantuvo una orientación socialista o filo-socialista, como se puede apreciar en una revista como Los libros de Argentina, sobre todo en la etapa politizada, bajo la dirección de Beatriz Sarlo y Carlos Altamirano.

El carácter problemático de su literatura se encuentra determinado por la tensión e incluso la contradicción entre estos dos planos. Por un lado, Sarduy rompe con la representación y trabaja con milimétrica artificialidad la prosa, poniendo en crisis conceptos como nación, ser humano y normalidad sexual. De acuerdo con el programa que Gilles Deleuze y Felix Guattari presentaron en El Antiedipo (1974), el neobarroco propone una aceleración revolucionaria del capital. Nada lo refleja mejor que una de las principales diferencias que mantuvo con José Lezama Lima. Aunque la obra inmensa que éste desarrolló no puede reducirse a una sola actitud ideológica, uno de sus rasgos dominantes es, como demostró Duanel Díaz Infante (2005), la defensa de los mojones tradicionales (la familia, la comunidad barrial, el casco colonial de La Habana Vieja) que el capitalismo amenazaba con destruir. En Sarduy esta nostalgia no sólo desaparece, sino que el escritor articula su escritura con la homosexualidad, la artificialidad y la densificación de los signos ya densificados del tejido urbano para detonar esas herencias históricas del capitalismo clásico. Pero, al mismo tiempo, la propuesta de Sarduy sólo podía desarrollarse en sociedades democráticas y liberales. Por supuesto, se coloca en los focos de resistencia al poder: no es un defensor de las virtudes del capitalismo, sino un escritor que apunta a aquello que se resiste a los anclajes dominantes. Pero las resistencias en las que se apoya no son externas a la sociedad, sino que, como demuestra Foucault (1998) en La voluntad de saber, forman una red con el poder diseminado y son fundamentales para su 
organización. En este sentido, la obra de Sarduy tiene una relación soterrada con el sistema de poder al que se opone.

Este lugar complejo se define de una manera clara en la revista Mundo Nuevo, en la que Sarduy publicó los ensayos que luego recogería en Escrito sobre un cuerpo. Creada y dirigida, entre 1966 y 1968, por Emir Rodríguez Monegal, Mundo Nuevo construyó un espacio nítido en lo que respecta a la política y el campo intelectual. Como demuestra María Eugenia Mudrovcic (1997), la revista pertenecía al Congreso por la Libertad de la Cultura, una institución anticomunista, e inicialmente recibió, por vías indirectas, fondos de la CIA. Pero a pesar de estos vínculos oscuros, lo cierto es que Mundo Nuevo se propuso superar las disyuntivas tradicionales para conectar, y al mismo tiempo fomentar, la modernidad latinoamericana. Interpeló al público nacido de la masificación de las políticas educativas, se ocupó de los principales temas de la actualidad, incorporó las nuevas teorías literarias y le prestó atención a la floreciente industria del libro. Asimismo, Rodríguez Monegal se propuso superar los dilemas de la Guerra Fría para desarrollar una concepción liberal renovada. En una crónica sobre el congreso del PEN Club, celebrado en 1966 en Estados Unidos, el crítico destaca que su director, Arthur Miller, consiguió la participación de "escritores de los países socialistas del mundo entero y, sobre todo, de una delegación latinoamericana en que abundaban los escritores de izquierda" (RODRÍGUEZ MONEGAL, 1996: 86). Para Monegal, la apertura fue "la mejor demostración de que el maccartismo había sufrido una gran derrota póstuma en los Estados Unidos y de que la Guerra Fría (por lo menos en el terreno intelectual) había dado paso al diálogo" (1966: 86).

A pesar de lo que se podía esperar de él, Sarduy no ocupó el lugar que era previsible como exiliado cubano. En el espacio moderno e internacionalista de Mundo Nuevo, no se convirtió en un opositor rabioso del socialismo ni celebró las bondades del capitalismo, sino que se interesó por el erotismo, las nuevas teorías y las vanguardias plásticas y elaboró con esos materiales una concepción nueva de la literatura y la revolución. En "Por un arte urbano", aparecido el número 25 , expone este programa, que seguirá hasta mediados de los años ochenta, a través de una interpretación histórica de la ciudad. De acuerdo con su punto de vista, hasta el siglo XVI las ciudades se organizaban con una topología en ángulo recto alrededor de la plaza central, en donde se situaban la casa de gobierno y la catedral. El Barroco trastocó esta organización: se formaron barrios, aglomeraciones, paseos y nuevos lugares de sociabilidad, de modo que el cuadriculado y la plaza perdieron sus privilegios y los habitantes se vieron inmersos en una metrópoli difícil de imaginar en su totalidad.

El ensayo sigue una lógica anacrónica, de acuerdo con una impronta que va a continuar en Barroco, porque está claro que es imposible pensar 
la cultura del Barroco como un proceso revolucionario que destituye los poderes de la Iglesia y la monarquía. Por este motivo, Sarduy se refiere casi de inmediato al presente, afirmando que ya no es posible imaginar la ciudad en su conjunto sin la mediación de mapas, guías y relatos, ni se la puede ordenar sin el empleo de símbolos, íconos, leyendas y numeraciones. Para Sarduy, la metrópoli es un texto, y lo es de manera metafórica y literal: es una red sin centro y es un espacio definido por la semiología. A partir de esto, compone una teoría política. El orden clásico, que es el del capitalismo que heredan los años sesenta, se organiza a partir del centro, ocupado por la casa de gobierno y los núcleos de los que emana la ideología. Como en su imagen anacrónica del Barroco, la ciudad actual muestra que el poder se fuga de la plaza central y deja de pertenecer a una autoridad concreta para trasladarse al lenguaje. A partir de esto, presenta una nueva teoría de la revolución: ésta ya no pasa por el derrocamiento material de un gobierno, sino por la deconstrucción que llevan adelante el arte, la literatura y las nuevas concepciones de la subjetividad ${ }^{3}$.

Cobra, o la nueva forma de la revolución

El despliegue del programa estético-político de Sarduy se encuentra en Cobra (1972). En esa tercera novela, Sarduy se desentiende de los sustentos tradicionales de la narrativa. En lugar de presentar una historia representativa, cuenta una anécdota mínima y, en el contexto, escandalosa: un travesti que trabaja en un teatro quiere convertirse en mujer. Fiel a su visión de que lo político se encuentra en los sistemas de signos, Sarduy traslada el argumento al lenguaje: Cobra es una superficie libre de transformaciones textuales.

El punto clave de su experimentación se encuentra en el personaje. Para subrayar el tema, en La estrategia neobarroca Gustavo Guerrero (1987) hace una breve historia de esta figura. De acuerdo con el crítico, desde Jane Austen a Fiódor Dostoievski, el personaje gana el centro de la escena en tanto el foco del texto comenzó a afianzarse alrededor de los dramas y las contradicciones de los protagonistas. Esta carrera comienza a declinar con Proust y Kafka y se vacía con el Nouveau Roman, que pone en crisis la identificación entre personaje y persona. Para Guerrero, Sarduy da un paso más: compone y descompone "a placer, página en página, una serie de criaturas en constante metamorfosis que representan una burla del "efecto-personaje" dentro del texto" (1987: 113). En Cobra, el escritor llega al punto más alto de esta propuesta. La primera imagen que tenemos del/la protagonista es la de una travesti que actúa en el "Teatro Lírico de Muñecas”. Como sugiere el nombre

${ }^{3}$ Esta nueva idea de la revolución relumbra en una carta a Díaz Martínez de agosto de 1970: "la actitud subversiva de la poesía está en la des-construcción de eso que para "los otros" es paradigma de la normalidad, de la percepción y la lógica: el lenguaje" (1996: 44). 
del establecimiento, los integrantes de la troupe están en una zona difusa entre el género humano y los muñecos de plástico. En lugar de peinarse, Cobra "se alisaba las enmarañadas fibras de vidrio" y se arreglaba con pestañas postizas, pigmentos y lentes de contacto amarillos (SARDUY, 1999: 428).

En paralelo, Sarduy elimina la estructura familiar. Como demuestra Roberto González Echevarría, el conjunto de sus personajes "se constituye de manera más bien fortuita, y estos se relacionan o reproducen de forma teogónica, nunca de la manera biológica convencional" (1997: 61). Esta ausencia está ligada a otra, que González Echevarría destaca en La ruta de Severo Sarduy: la falta de "un foco de sentido que cohesione los elementos que lo arman” (1987: 155). Por esta razón, en Sarduy "el lenguaje está constantemente lanzando destellos de significación que no son recuperables desde un centro emisor o receptor" (1987: 155). Entre estas dos observaciones, la falta de un foco de sentido y la ausencia de grupos familiares, existe una importante relación. En la novela del siglo XIX, la familia es determinante para la trama y todavía la narrativa del boom es en parte una novela familiar: la familia, el foco de sentido y los vínculos entre personaje y persona conforman un todo.

Si Sarduy rompe con esta forma tradicional, podemos dar un paso más allá de González Echevarría para señalar que lo logra manteniendo un foco de organización, que toma de la conceptualización de Jacques Lacan. Aunque Lacan expuso con claridad los tiempos del Edipo, discutió con insistencia la reducción del psicoanálisis a la historia de un mito, motivo por el cual prefirió hablar de castración. El concepto está ligado a la inversión del signo lingüístico y es el eje por medio del cual crea el punto de capitón, que presenta por primera vez en Las formaciones del inconsciente (LACAN, 1999). De acuerdo con esta perspectiva, los significantes se encuentran flotando hasta que alguno logra subordinarlos para crear una articulación. En Cobra, Sarduy propone un trabajo libre a partir de esta estructura, elaborando lo que podemos llamar un "texto esquizofrénico". Si en Lacan la castración es un corte metafórico irreversible, en Sarduy los operadores del lenguaje, dibujados en el cuerpo, pueden borrarse a poco de ser trazados. Como la metáfora es perecedera, los personajes se arman y desarman según las modulaciones del lenguaje.

En las primeras páginas de la novela, en las que mezcla teoría literaria y narración, Sarduy asume esta estructura por medio de una serie de enunciados que fundan diferentes historias de vida de un personaje llamado Eustaquio. Por ejemplo, la novela sentencia que "La escritura es el arte de la digresión". Con olor a hachís y curry, con "un basic english", Eustaquio es un indio costumista que oficia como vestuarista de la compañía teatral. En lugar de vestir a las actrices, las pinta con arabescos y les escribe, en los dedos, "los textos de entrada a escena" (1999: 432). Pero enseguida la novela plantea que "La escritura es el arte de recrear la realidad". El personaje se transforma, entonces, en una figura híper masculina: "No ha llegado el artífice himalayo, 
como se dijo, alhajadito y pestiferante, sino con un recién planchado y viril traje cruzado color crema -en la corbata de seda una torre Eiffel y una mujer desnuda acostada sobre el letrero Folies Chéries" (1999: 432). Luego la novela niega de manera rotunda esta versión. Afirma que "La escritura es el arte de restituir la Historia” y presenta una biografía del personaje. En esa oportunidad, Eustaquio es un viejo luchador de la corte de un maharajá perteneciente a Cachemira. Después de una revolución escapa con una maleta repleta de joyas que dilapida en burdeles y apuestas pugilísticas. En Benarés anima una escuela de lucha y en Ceilán se dedica al comercio de infusiones. Pasa luego a Colombo, donde se gana la vida como concesionario de especies, hasta que huye al perder una pelea. En Esmirna reduce a golpes a seis luchadores turcos. En un lupanar, recibe el apodo de Eustaquio por parte de la matrona del Teatro Lírico de Muñecas (se trata de un griego obeso, de taco alto y flor en el pelo). Con ese nombre, pasa a Occidente y se dedica al contrabando de marfil en los rastros judíos de Copenaghe, Bruselas y Amsterdam, ciudades cuyas letras iniciales forman el nombre de la novela. Cultiva entonces "un inglés clásico y unos cabellos negros y brillantes que, sobresaliendo de un bonete de gamuza verde, se continuaban con una barba oficialmente oriental" (1999: 434). En "La escritura es el arte de descomponer un orden y componer un desorden", la Señora del Teatro Lírico lo encuentra en un baño turco de Marsella y aparece de nuevo con "plena posesión de su pericia escriptural" (1999: 435). Pero una vez que ha dado las últimas puntadas de esta biografía, hay un nuevo golpe y, debajo de "La escritura es el arte del remiendo", desmiente todo lo dicho:

¡Sólo un tarado pudo tragarse la, a todas luces, apócrifa historieta del pugilista que, de buenas a primeras, aparece en un cuadro flamenco y renuncia a su fuerza de macho de pelo en pecho nada menos que para encasquetarse un bonete verde y ponerse a traficar florines! ${ }$ Vamos, hombre!

Es cierto que Eustaquio amenizó la corte de un maharajá, pero, como era de esperarse, en tanto que bailarina desnuda y coreógrafo ritual; es cierto que peina "seda de caballos": la guarnece de claveles -que se pega con scotch tape- para bailar bulerías (1999: 440).

Cobra pone en juego una metáfora que cambia de manera plástica de acuerdo con los axiomas de la novela. Eustaquio, el encargado de pintar los cuerpos, es el símbolo consumado: es un personaje que se transforma según la puntada significante desde la cual se reconstruye su vida. Por esta vía, Sarduy presenta una concepción revolucionaria que opera sobre la literatura y la sociedad. Sobre la literatura, porque destituye la subordinación del texto a la realidad; sobre lo social, porque revela que la subjetividad es el efecto de una estructura simbólica en constante mutación. 
En El pliegue (1989), Deleuze afirma que en la actualidad retorna el poder explicativo de la mónada. El concepto de Leibniz permite pensar la música, la literatura, los sistemas informáticos, la plástica y las cadenas de ADN. Como subraya el filósofo, esta vuelta conlleva, sin embargo, un cambio nodal. En el 1600, la mónada se encuentra cerrada y en su interior está alojado el mejor de los mundos posibles; en la actualidad la mónada está abierta y afirma varios mundos posibles a la vez. Escrita casi dos décadas antes, Cobra se anticipa a esta perspectiva. Las transformaciones libres que Sarduy le imprime al personaje son significativas porque, en lugar de contener el mundo en su interior, revelan que es una superficie abierta y neoleibniziana, en la que se entretejen las series culturales y sociales que componen la estructura simbólica y abierta de la ciudad.

Hoy en día podemos constatar que la revolución que encarnan Sarduy y Deleuze termina cristalizada. Los personajes del escritor cubano y las mónadas neoleibnizianas se parecen al mundo de Internet: el sujeto participa de realidades divergentes gracias a las informaciones que vienen de afuera y puede subjetivarse de acuerdo con las modulaciones del deseo. No se trata de una libertad, tampoco de una revolución, sino de un nuevo orden cultural. Deleuze llegó a conclusiones similares en "Post-Scriptum sobre las sociedades de control" (1990). En ese ensayo, el filósofo recuerda que la sociedad disciplinaria se basaba en los moldes de la prisión, el manicomio, la escuela y la fábrica. Estos compartimentos, podemos agregar, se organizaban a partir de la lógica clásica de las mónadas, pues se encuentran cerrados (son formas de encierro), y contienen el mundo en su interior, porque la escuela, el manicomio o la prisión mantienen un mismo modelo subjetivo y en conjunto organizan un mismo mundo social. La revolución cultural operó contra todo esto: tanto los devenires minoritarios como el neobarroco trabajaron con las partes caídas del sistema. Si seguimos al Deleuze de "Post-Scriptum", esa revolución logró triunfar, pero ese triunfo se revela equívoco, porque produjo el orden nuevo de la sociedad de control. A diferencia de la rigidez disciplinar, las sociedades de control se basan en un "moldeado autodeformante" (1990: 279). El sistema ahora es neoleibniziano: ya no trabaja con el cierre de las mónadas, sino que las mónadas, desde las instituciones a los individuos, están abiertas al exterior, de modo que el deseo, lejos de estar prohibido, conecta con el capital y se transforma en una fuerza ordenadora. La sociedad es una red de poder/resistencia, un rizoma barroco que logra imponerse por la forma cambiante que esa dinámica le proporciona.

En Sarduy, este pesimismo aparece más temprano. En una entrevista de 1985, el escritor le comenta a Julio Ortega que, tras salir de una exposición 
en Nueva York, se dio cuenta de que en las principales capitales del mundo ya no despierta interés "crear una significación, literaria o plástica, que resulte subversiva, irrecuperable, y que, de un modo u otro, amenace el sistema establecido, el confort, el pensamiento común”“. A los 48 años, con una obra cuyas dimensiones son tan valiosas como la coherencia interna que la estructura, Sarduy ya no se encuentra reflejado por el mundo, por lo menos no por el mundo "superdesarrollado", porque los artistas han abandonado la revolución. Pero en Sarduy, este pesimismo se anuncia desde más atrás. Para verlo, vale la pena detenerse en La simulación (1982).

En ese libro, Sarduy repone los principales argumentos de la revolución neobarroca: la simulación, la anamorfosis, el cuerpo y el travestismo. La primera página, una viñeta autobiográfica en la que describe con obsesiva minuciosidad una fotografía, es el ejemplo más destacable de su prosa barroca. Lo mismo podemos decir de sus ideas sobre el travestismo, en las que conecta el concepto con lo animal, de acuerdo con argumentos que, tomados de Lacan y Roger Caillois, reenvían, a futuro, a la biopolítica de Giorgio Agamben (2007). Pero el libro también muestra que las reflexiones sobre el arte y la literatura comienzan a quedar circunscritas al campo estético y dejan de tener impacto más allá de él. De particular importancia, en este sentido, son sus reflexiones sobre Robert Rauschenberg. Para Sarduy, Rauschenberg es la última expresión de las tensiones con las cuales el siglo XX transformó la institución arte mediante el uso de objetos ajenos a ella. Según resume en el ensayo, la revolución la inician los futuristas y llega a la cúspide con Duchamp. A mediados de siglo queda restringida al campo estético y termina por convertirse en la lógica que ordena el arte. Cuando Rauschenberg hace su primera exposición (1950), se integra en lo que "es ya una tradición: desconstitución de la imagen, práctica del arte por el absurdo, subversión de toda lógica del cuadro" (SARDUY, 1999: 1326). Por supuesto, el artista reabre el marco a nuevas formas: Rauschenberg incluye los detritus que dejamos en lo cotidiano, poniendo en crisis los fundamentos del arte occidental, ya que no trabaja con la imagen, sino con su destrucción. Pero a la vez se percibe, en esta lectura, que la mirada se restringe, como si la revolución quedara encerrada en los museos.

Otro tanto se advierte en "Jeroglífico de muerte". En su versión original, el ensayo es un catálogo para la exposición de las muñecas que realiza Marta Kuhn Weber en la Galerie 13 en 1973. Aunque todavía nos encontramos en pleno programa revolucionario, en un pasaje Sarduy se refiere a la institución arte y comprende la dinámica por la cual se incorporan objetos externos a ella mediante el concepto de "metáfora al cuadrado":

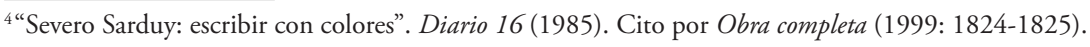


Sin duda ese paso -el del objeto en bruto al objeto de arte- es el efecto de una veladura, de una erosión brusca: algo se borra. Se eliminan, o al menos se metaforizan, se transponen-que es el verbo que siempre se emplea en el vocabulario al uso, estetizante o no- todas las marcas que en el objeto indicaban el síntoma puro. Se practica, para franquear la clausura del arte, una metáfora al cuadrado, pues el síntoma es ya una metáfora (SARDUY, 1999: 1320).

En Escrito sobre un cuerpo y Barroco (1974), la "metáfora al cuadrado" designa el proceso subversivo por el cual el significante rompe con el referente y se conecta con los deseos reprimidos. En este texto sobre Marta Kuhn Weber, la idea aplica en cambio a la institución arte y tiene un sentido negativo: si la imagen es un síntoma, los museos la controlan, al cruzarla con la gran metáfora de la institución.

$\mathrm{Si}$, en los años '70, el neobarroco articula la palabra con las partes caídas de la sociedad, si, para decirlo con Jacques Rancière (2011), abre la esfera de lo sensible para incorporar en lo político nuevos sujetos y objetos, estas operatorias, en red con los grupos minoritarios, generaron un desorden, pero también un reordenamiento de la cultura. La sociedad liberal abandonó las viejas fuentes de legitimidad (la nación y las identidades preestablecidas) y asumió las tensiones como una lógica ordenadora. En este aspecto, "Por un arte urbano" puede desvincularse de su sentido programático para convertirlo en una descripción de la contemporaneidad. En la sociedad actual, el poder efectivamente se diseminó en los lenguajes. Aunque el nuevo orden puede suturar los conflictos, recordando la nación o poniendo de relieve determinados mitos, y aunque se organiza en núcleos densos, como el Estado o los anclajes institucionales, deja de ser un discurso prohibitivo y se convierte en una máquina que controla gracias a que captura los deseos. El deseo se articula con la demanda, es decir, se articula con los lenguajes que nos constituyen, pero a la vez es irreductible a ella. Esa falla es lo que hace a una sociedad incompleta. Pues bien, las sociedades de control ordenan las subjetividades a partir de la diferencia entre el deseo y la demanda, el poder y la resistencia, estableciendo una revolución permanente del capital.

\section{Desengaño y autobiografía}

En "Fractura del monólogo", uno de los ensayos de La simulación, Sarduy sostiene que, en los autorretratos del artista Enrique Broglia, hay una "perturbación del mensaje facial que sin ella se volvería más nítido, puntual, unido, sin quebraduras" (1999: 1317). Esa tachadura del rostro, "que viene a introducirse como un suplemento ruidoso" (1999: 1317), es para Sarduy la escritura. En esta oportunidad, retoma la concepción que Lacan (2012) 
expone en "Lituraterre": la escritura es la huella que deja el significante cuando el sujeto entra en el lenguaje, marca singular, barra que se escribe para dividir las dos caras del signo lingüístico. La escritura, como forma sintomática, como nudo proliferante y generativo, se distingue del significante porque, cuando se repite, no se diferencia, sino que, como aquello que no cesa de escribirse, vuelve siempre de la misma manera.

El trabajo sobre Broglia puede pensarse como una bisagra en la obra de Sarduy, independientemente de las fechas y las intenciones del ensayo, porque proyecta dos caminos posibles. El primero es la reinscripción del programa de la revolución. Sarduy utiliza la noción lacaniana de escritura para reactualizar su lucha contra la identidad como forma de revolucionar la cultura, aspecto que se encuentra plasmado en que, en Broglia, ese trazo, cada vez más firme, produce esferas agrietadas, "islotes faciales" que muestran las "ruinas de la identidad" (1999: 1318). Pero al imponerse la lógica de control, la comprobación de que el individuo es hablado por el lenguaje cambia de sentido, porque muestra que la amplificación de los discursos es la nueva forma de dominación. Entonces, la escritura se convierte en marca singular, que vuelca el neobarroco hacia la autobiografía. En el último Sarduy, la metáfora loca deja paso a la huella imborrable, herida o cicatriz, que no cesa de escribirse en el cuerpo y que define una subjetividad.

El escritor despliega esta perspectiva en El Cristo de la rue Jacob (SARDUY, 1986). En la presentación, Sarduy sostiene que las dos partes del libro, "Arqueología de la piel" y "Lección de lo efímero", están unidas por la idea de la huella. La primera está compuesta por fragmentos en los que recuerda cómo se produjeron las cicatrices que tiene en el cuerpo. Sarduy afirma que se trata de una escritura, en el sentido de que la cicatriz es lo que no cesa de escribirse de Lacan: "Sólo cuenta en la historia individual lo que ha quedado cifrado en el cuerpo y que por ello mismo sigue hablando, narrando, simulando el evento que lo inscribió" (1999: 51). En la segunda parte, una miscelánea de ensayos, propone motivaciones autobiográficas, regidas por las huellas que han "quedado en la memoria de un modo más fuerte que el recuerdo aunque menos que la obsesión" (1999: 51). En "El Libro Tibetano de los Muertos", una de las entradas de la segunda parte, cuenta que en el Tíbet compra un pesado volumen con el que inicia una agenda. Al poco tiempo se suicida Calvert Casey. Entonces se da cuenta de que no puede borrar su nombre, porque "sería como anularlo de nuevo, como entregarlo, cómplice de la vacuidad, a otra muerte dentro de la muerte, excluyéndolo para siempre del día azul de tinta” (1999: 84). Para 1986, se han agregado Héctor Murena, María Rosa Oliver, Rolland Barthes, José Lezama Lima, Virgilio Piñera, Witold Gombrowicz, Italo Calvino, Emir Rodríguez Monegal y José Bianco. Varios de estos nombres pertenecen a los amigos de los años sesenta y setenta, en los 
que la escritura articulaba con la revolución. En la agenda, conforman ahora un panteón, que clausura la época revolucionaria del escritor.

Desde El Cristo, Sarduy abandona la escritura milimétrica de Maitreya y Colibri y comienza a utilizar una frase precisa, orientada a la sentencia. Se trata de un estilo que, en Agudeza y arte de ingenio, Baltasar Gracián denomina lacónico. A través de Lacan, Sarduy lo conecta, además, con la herida y la autobiografía. Cocuyo es el mejor exponente de esta nueva articulación. En esa novela, la última que publicó en vida, Sarduy retoma el drama familiar y utiliza los ejes clásicos de la narrativa. En una entrevista con Gustavo Guerrero, afirma, asimismo, que Cocuyo "no es una autobiografía, aunque todos los detalles son reales, sino más bien lo que se llama, en un fresco, la sinopia, la base gráfica, el trazo primero y su desmesurada consecuencia en el sentir y el percibir de un niño, de Cocuyo" ". En sus papeles autobiográficos, Sarduy revela dos trazos que conectan su vida con la del personaje: ambos se enamoran de una muchacha que se llama Ada y coleccionan postales del Album de Oro Zoológico ${ }^{6}$. La novela no es una autobiografía, sino una escritura autobiográfica: Sarduy toma algunas de las huellas de su vida y compone una historia distinta ensamblada en un mundo de ficción.

Como en sus anteriores novelas, en el relato cuenta una rebeldía (Cocuyo atenta contra la familia, como Sarduy lo había hecho desde la literatura), pero ahora el rebelde se derrumbe en el fracaso. Después de un capítulo que tiene el significativo título de "La desilusión", Cocuyo descubre que la chica de la que se había enamorado fue vendida a un teatro pornográfico. Su sola mención recuerda el Teatro Lírico de Muñecas y el burlesco de De donde son los cantantes, pero nada queda de esas antiguas celebraciones. Cocuyo huye a los golpes del lugar, para descubrir, una vez afuera, que está herido: "Estas heridas -dijo en voz alta-, no voy a curarlas. Son las marcas de la mentira, las firmas en mi cuerpo de la indignidad" (1999: 913). Sarduy abandona la metáfora loca y une la escritura a la herida imborrable de la desilusión.

Esta visión llega a la cúspide en El estampido de la vacuidad (1999). En ese cuaderno, que Sarduy escribe en los últimos momentos de su vida, recuerda las huellas dramáticas que le quedan de la vida. Con el laconismo de su última época, anota fragmentos precisos, de una notable nitidez, como si cada uno fuera una cicatriz. Habla de los martirios que sufrió San Juan, la imposibilidad y la esperanza de creer en Dios, las heridas profundas que le causaron el rechazo de su obra y el exilio, palabra que repite pocas veces, casi sin dramatismo, lo cual le da un dramatismo tal vez mayor. En el segundo

\footnotetext{
5"Reflexión, ampliación, cámara de eco: entrevista con Severo Sarduy". Diario de Caracas (1993). Cito por Obra completa (1999: 1835).
}

'Sarduy explicita estos enlaces en "Para una autobiografía pulverizada..." (1999: 11) y "Así me duermo..." (1999: 32-33). 
fragmento, afirma que su vida no ha tenido ningún destino, pues ha escrito libros que nadie leyó, pintado cuadros que nadie compró y tenido ardores que ningún cuerpo pudo calmar; luego rectifica: "Cómo no ver en esta sucesión de frustraciones, de fracasos, enfermedades y abandonos, el golpetazo reiterado de la mano de Dios" (1999: 105). Al borde de la muerte, Sarduy describe, o mejor dicho, encarna en la escritura, las cicatrices que le han dejado los golpes de la vida.

\section{La elipse de la revolución}

En varias oportunidades, Lacan y Sarduy se refieren a la astronomía de los siglos XVI y XVII. Ambos destacan la gran innovación de Copérnico, pero la matizan, afirmando que su obra no constituyó una verdadera revolución, porque mantuvo la idea de que la órbita de los planetas describe un círculo perfecto alrededor de un eje central. Por eso reivindican la fuerza disruptiva de la elipse kepleriana. En Aun, Lacan sostiene que la subversión "no está en haber cambiado el punto de rotación de lo que gira”, es decir, en reemplazar, como Copérnico, la tierra por el sol, "sino en haber sustituido un gira por un cae" (LACAN, 2001: 56). Para Kepler, los planetas se mueven en elipse: "caen hacia algo que está en un punto de la elipse llamado foco, y, en el punto simétrico, no hay nada" (2001: 56). Como ratificó Sarduy, la elipse sirve para pensar la subversión que siglos más tarde haría el psicoanálisis, porque muestra el desdoblamiento del sujeto, entre los focos de lo consciente y lo inconsciente.

En este trabajo he recordado algunos de los momentos de la dimensión revolucionaria del escritor y las causas por medio de las cuales ésta a la vez triunfó y se disolvió. Al echar una mirada hacia el recorrido que he propuesto, el esquema kepleriano permite diseñar una visión de conjunto y establecer algunas breves conclusiones. En primer lugar, la obra de Sarduy se mueve en elipse: al principio rompe con la subjetividad y las formas clásicas de la narrativa y luego retorna a una recuperación de lo subjetivo y la intimidad. Este movimiento hacia lo autobiográfico no significa una vuelta a la situación prefreudiana. Si abstraemos de su obra la cronología, la elipse de Sarduy se organiza alrededor de la escritura, en el sentido lacaniano del término: en los años '60 y '70 subvierte el sujeto, dirigiéndose a la cada vez más densa red de significantes, y desde los ' 80 retorna a la subjetividad, no ocupándose del alma o los sentimientos, sino de las pasiones causadas por las marcas que el lenguaje deja en el cuerpo y la memoria. La elipse también permite comprender los vínculos de su trabajo con el sistema cultural. En Mundo Nuevo, Sarduy establece los dos focos alrededor de los cuales se organiza su escritura: el primero es la subversión, que él lidera, y el segundo, el desarrollo 
de un nuevo orden social, por el que brega Emir Rodríguez Monegal. En esta época se instala la red de poderes y resistencias que van a subvertir y al mismo tiempo transformar el orden, para constituir lo que Deleuze llama la sociedad de control. La rotación de su obra, y de manera más general la rotación de la cultura, dibuja, entre el momento inicial y el final, lo que en retórica se llama un quiasmo: en el momento revolucionario, Sarduy cuestiona el sujeto y afirma el poder subversivo de los lenguajes, mientras que en el momento de decepción afirma el sujeto como resistencia y cuestiona los lenguajes en tanto organizan la nueva forma de dominación.

En El estampido de la vacuidad, Sarduy sostiene que su vida ha sido un fracaso. Podemos aceptar una afirmación semejante si tomamos en cuenta que quien escribe es un moribundo; para nada si miramos la dimensión intelectual de su trabajo. Sarduy cuenta con un raro privilegio: en él se encuentran los signos más destacables de la historia política, literaria e intelectual de la segunda mitad del siglo XX. Además, aunque muchos de sus libros están demasiado ligados al contexto en que los produjo, en ellos desarrolló una forma de pensar la sociedad que anticipa los enfoques de Ernesto Laclau y Chantall Mouffe (1987) y Slavoj Zizek (2003), y vislumbró dos de los ejes centrales de la estética actual: de un lado, el cuerpo, las relaciones con la política, las intervenciones artificiales y los vínculos con lo animal, y, del otro, lo subjetivo o lo íntimo, de tanta importancia en la literatura contemporánea. No es poco, hay que reconocerlo, para un escritor.

\section{Referencias Bibliográficas}

AGAMBEN, Giorgio. Lo abierto. Buenos Aires: Adriana Hidalgo, 2007.

BARTHES, Roland. Crítica y verdad. México D.F.: Siglo XXI, 1996.

."La face baroque". [1967] In: SARDUY, Severo. Obra Completa. ed. crítica de Gustavo Guerrero y François Wahl (Coords.). Madrid: ALLCA XX/Scipione Cultural, 1999: 1729-1730.

DELEUZE, Gilles; GUATTARI, Félix. El Antiedipo. Buenos Aires: Corregidor, 1974.

DELEUZE, Gilles. El pliegue. Barcelona: Paidós, 1989.

. "Post-scriptum sobre las sociedades de control". In: DELEUZE, Gilles. Conversaciones. Valencia: Pre-textos, 1996: 277-286.

DÍAZ INFANTE, Duanel. Los límites del origenismo. Madrid: Colibrí, 2005.

ECHEVERRÍA, Bolívar. La modernidad de lo barroco. México: Era, 1998.

FOUCAULT, Michel. La voluntad de saber. Buenos Aires: Siglo XXI, 1998.

GILMAN, Claudia. Entre la pluma y el fusil. Buenos Aires: Siglo XXI, 2003. 
GRACIÁN, Baltasar. Agudeza y arte de ingenio. En: GRACIÁN, Baltasar. Obras completas. Buenos Aires: Poblete, 1943: 95-580.

GONZÁLEZ ECHEVARRÍA, Roberto. La ruta de Severo Sarduy. Hanover: Ediciones del Norte, 1987.

. "La nación desde De donde son los cantantes a Pájaros de la playa", Cuadernos hispanoamericanos, Madrid, n. 563, 1997: 55-70.

GUERRERO, Gustavo. La estrategia neobarroca. Barcelona: Del Mall, 1987.

LACAN, Jacques. Las formaciones del inconsciente. Buenos Aires: Paidós, 1999. . Aun. Buenos Aires: Paidós, 2001.

. "Lituratierra". En: LACAN, Jacques. Otros escritos. Buenos Aires: Paidós, 2012: 19-32.

LACLAU, Ernesto; MOUFFE, Chantal. Hegemonia y estrategia socialista. Madrid: Siglo XXI, 1987.

MUDROVCIC, María Eugenia. Mundo Nuevo. Rosario: Beatriz Viterbo, 1997.

Mundo Nuevo. 1o época. París. 1966-1968.

POGOLOTTI, Graziela. Polémicas culturales de los '60. La Habana: Letras Cubanas, 2006.

RODRÍGUEZ MONEGAL, Emir. "El P.E.N. Club contra la guerra fría“, Mundo Nuevo n 5, París, noviembre 1966: 85-90.

RANCIÈRE, Jacques. Politica de la literatura. Buenos Aires: El Zorzal, 2011.

ROJAS, Rafael. La vanguardia peregrina. México D.F.: FCE, 2013.

SARDUY, Severo. Cartas. Madrid: Verbum, 1996.

. Obra Completa. ed. crítica de Gustavo Guerrero y François Wahl (Coords.). Madrid: ALLCA XX/Scipione Cultural, 1999. 2 vol.

. Severo Sarduy en Cuba. Santiago de Cuba: Editorial Oriente, 2007.

ZIZEK, Slavoj. El sublime objeto de la ideología. Buenos Aires: Siglo XXI, 2003.

Ignacio Iriarte. É professor da Universidad Nacional de Mar del Plata (Argentina) e pesquisador do Consejo Nacional de Investigaciones Cientificas y Técnicas (CONICET). Tem doutorado pela Universidad de Buenos Aires. Autor de inúmeros artigos em revistas e capítulos de livros sobre o neobarroco latino-americano. Secretario de redação da revista El jardín de los poetas e do sitio web Caja de resonancia. Seu próximo livro, Del Concilio de Trento al sida. Una historia del Barroco, em edição pela Editorial Prometeo encontra-se no prelo.

E-mail: iriarteignacio@yahoo.com.ar

Recebido em: 12/09/2016

Aprovado em: 03/12/2016 